\title{
Relevance of Chromosome Number Variation to Yield and Quality of Essential Oil in Mentha arvensis L.
}

\author{
B. R. Tyagi and A. A. Naqvi \\ Central Institute of Medicinal and Aromatic \\ Plants, Post Bag No. 1, P.O. R.S.M. Nagar, \\ Lucknow-226016, India
}

Accepted February 25, 1986

Mentha arvensis L. is an aromatic plant from family Lamiaceae (Labiatae) and its oil is the richest source of menthol in tropical and sub-tropical areas of the world. The single compound menthol is used widely in medicinal, food and cosmetic preparations. Menthol is also used in the preparation of after-shave lotions, mouth washes and other toilet preparations and flavouring cigarettes. In India, it is taken with betels providing a cooling sensation when chewed.

This species of the genus Mentha (mint) is polymorphic and further complicated by gynodioecy, polyploidy and vegetative propagation. The plants are self-compatible and seed set occurs readily on self-pollination. However, a fairly high level of cross-pollination is assured due to gynodioecy. Although, the evolutionary aspect of $M$. arvensis has not yet been unraveled completely, its genesis has been considered through an ancient hybrid (Ikeda and Ono 1967).

Japanese mint ( $M$. arvensis $\mathrm{L}$. forma piperascens Holmes), the commercial source of natural menthol, has been cultivated in Japan for its essential oil since antiquity (Guenther 1949). Japan and China had been the suppliers of major quantities of world requirements of menthol before World War II. Subsequently, its cultivation was taken up in different parts of the world. China and Brazil have emerged as major suppliers of mint oil and menthol in the world market.

Japanese mint was introduced in India in 1954 from Japan (Handa et al. 1954, Kapoor et al. 1955, Dutta 1971). Currently it is cultivated on more than 8,000 hectares of land in Uttar Pradesh, Punjab and Haryana States, and the country is producing above 600 tons of this valuable essential oil annually, on the basis of which import of this item has been stopped. Inspite of the fact that the crop is vegetatively propagated, but over the years of multiplication of the same original material consisting of a few suckers of only one clone, there has been considerable qualitative deterioration in the oil, in terms of low percentage of menthol throughout the country (Mehra 1982, Husain 1982). During the last few years this deterioration has been so rapid that some of the small menthol producers have to close down their operation due to the non-availability of quality oil for processing. In view of this, we took up a programme for developing improved clone of Japanese mint capable of giving high oil yield with high menthol content through genetic manipulations. To overcome the problem of narrow genetic base of the existing material and to develop broad-based germplasm pool, a number of clones were introduced from various mint producing countries of the world. During the course of their multiplication, a few morphological variants (bud-sports) were identified. The results of an intensive study dealing with the variation in chromosome number, yield potential and oil quality of six distinct genotypes of $M$. arvensis are reported in this communication.

\section{Materials and methods}

The present study was conducted on six entries of $M$. arvensis from our germplasm collection. These included one locally cultivated clone (CIMAP/MA-2) originally introduced 
from Japan, three recent introductions (CIMAP/MA-3, CIMAP/MA-4 and CIMAP/MA-5 from Thailand, Taiwan and Brazil, respectively) and two bud-sports (CIMAP/MAS-1 and CIMAP/MAS-2) originated from Thailand clone CIMAP/MA-3.

The field experiment was conducted at the Institute during 1983. A randomized block design was adopted and the six clones were replicated three times. The sucker pieces were planted in rows in $4 \times 1.75 \mathrm{~m}$ plots. The distance between the rows was kept at $45 \mathrm{~cm}$. The basal dose of fertilizer was $40 \mathrm{~kg} \mathrm{~N}$ and $60 \mathrm{~kg}$ each of $\mathrm{P}_{2} \mathrm{O}_{5}$ and $\mathrm{K}_{2} \mathrm{O}$ per hectare. Eighty $\mathrm{kg}$ $\mathrm{N}$ per hectare was applied in four split doses. Regular cultural practices were adopted. The planting was done on 24th Jan. 1983 and two cuttings (first at 115 days after planting and second at 90 days after first cut) of the herbage were taken. The data on plant height, leaf/ stem ratio (by weight), fresh herbage yield, oil yield and congealing point of the oil were recorded at the time of each harvest and pooled for statistical analysis. Ten randomly selected plants in each plot were scored for plant height and leaf/stem ratio.

For determination of oil content, fresh herbage was hydrodistilled using Cleavanger apparatus. Oil samples were evalutaed for menthone, menthol and menthyl acetate by gas liquid chromatography (GLC) using Perkin-Elmer gas chromatograph model 3920 B equiped with TCD and a $2 \mathrm{~m} \times 1 / 8$ inch stainless steel column packed with $10 \% \mathrm{~K}-20 \mathrm{M}$ on chromosorb WNAW. Hydrogen flow rate was maintained at $28 \mathrm{ml} / \mathrm{min}$ and the analysis done at $130^{\circ} \mathrm{C}$. For plotting of chromatogram and processing of data HP-3390 A integrator was used. Identification of the peaks was done by coinjection of the compounds.

Somatic chromosome numbers were determined from root-tip cells. Actively growing root-tips were pre-treated with saturated aqueous alpha-bromonaphthalene for 4 hours at $4^{\circ} \mathrm{C}$ and fixed in ethanol-acetic acid $(3: 1)$ to which ferric chloride was added for 24 hours at room temperature. After thorough washing with water, root-tips were stained for 6 hours at $20^{\circ} \mathrm{C}$ in $2 \%$ acetocarmine and (N) $\mathrm{HCl}$ mixture $(9: 1)$ and then squashed in $45 \%$ acetic acid. Photomicrographs were taken from temporary squash preparations.

\section{Results}

The chromosome counts performed on root-tip cells of six morphologically distinct clones (Fig. 1) revealed that the somatic chromosome number in these genotypes was constant and ranged from $2 n=64$ to 108 (Table 1). The somatic chromosome numbers in locally cultivated clone-CIMAP/MA-2 (originally introduced from Japan), three new introductions namely CIMAP/MA-3 (from Thailand), CIMAP/MA-4 (from Taiwan) and CIMAP/MA-5 (from Brazil) and two bud-sports-CIMAP/MAS-1 and CIMAP/MAS-2 (originated from CIMAP/ MA-3) were observed as $2 n=84$ (Fig. 2A), 98 (Fig. 2B), 64 (Fig. 2C), 72 (Fig. 2D), 90 (Fig. 2E) and 108 (Fig. 2F), respectively. It was interesting to note that the marked variation in chromosome number of the two bud-sports CIMAP/MAS-1 (90 chromosome cytotype) and CIMAP/MAS-2 (108 chromosome cytotype), and their parental clone CIMAP/MA-3 (98 chromosome cytotype) was associated with the visible differences at morphological level of these genotypes.

The mean values for plant height, leaf/stem ratio, fresh herbage yield, oil content, oil yield, old quality and congealing point of oil of six clones are presented in Table 1. Plant height ranged from $50.633 \mathrm{~cm}$ to $83.133 \mathrm{~cm}$. The six genotypes were grouped into tall (CIMAP/MA-3 and CIMAP/MA-5), medium (CIMAP/MA-2) and dwarf (CIMAP/MA-4, CIMAP/MAS-1 and CIMAP/MAS-2) types in view of height differences. The leaf/stem ratio (by weight) was found to be highest $(59: 41)$ in CIMAP/MAS-1 followed by CIMAP/MAS-2 (58:42) and CIMAP/ MA-4 (52:48) while it was low (ranged from 46: 54 to $47: 53$ ) in the remaining three clones.

Both CIMAP/MA-3 and CIMAP/MA-5 gave significantly higher fresh herbage yield 


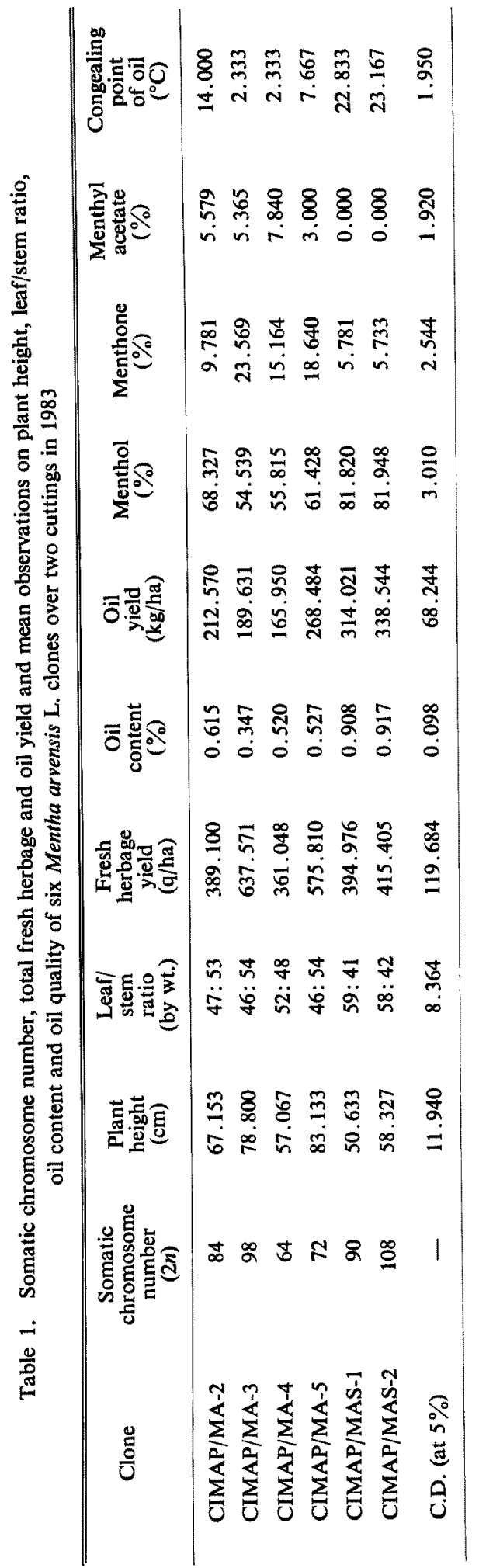


(637.571 and $575.810 \mathrm{q} /$ ha, respectively) than the rest which did not differ significantly from each other. However, lowest $(361.048 \mathrm{q} / \mathrm{ha})$ fresh herbage yield was recorded in case of CIMAP/MA-4. The oil content in the fresh herbage of CIMAP/MAS-1 (0.908\%) and CIMAP/ MAS-2 $(0.917 \%)$ was significantly higher as compared to other genotypes. The three clonesCIMAP/MA-4, CIMAP/MA-5 and CIMAP/MA-2 did not differ significantly from each other for oil content (range $0.520 \%$ to $0.615 \%$ ). The lowest oil containing $(0.347 \%)$ genotype was

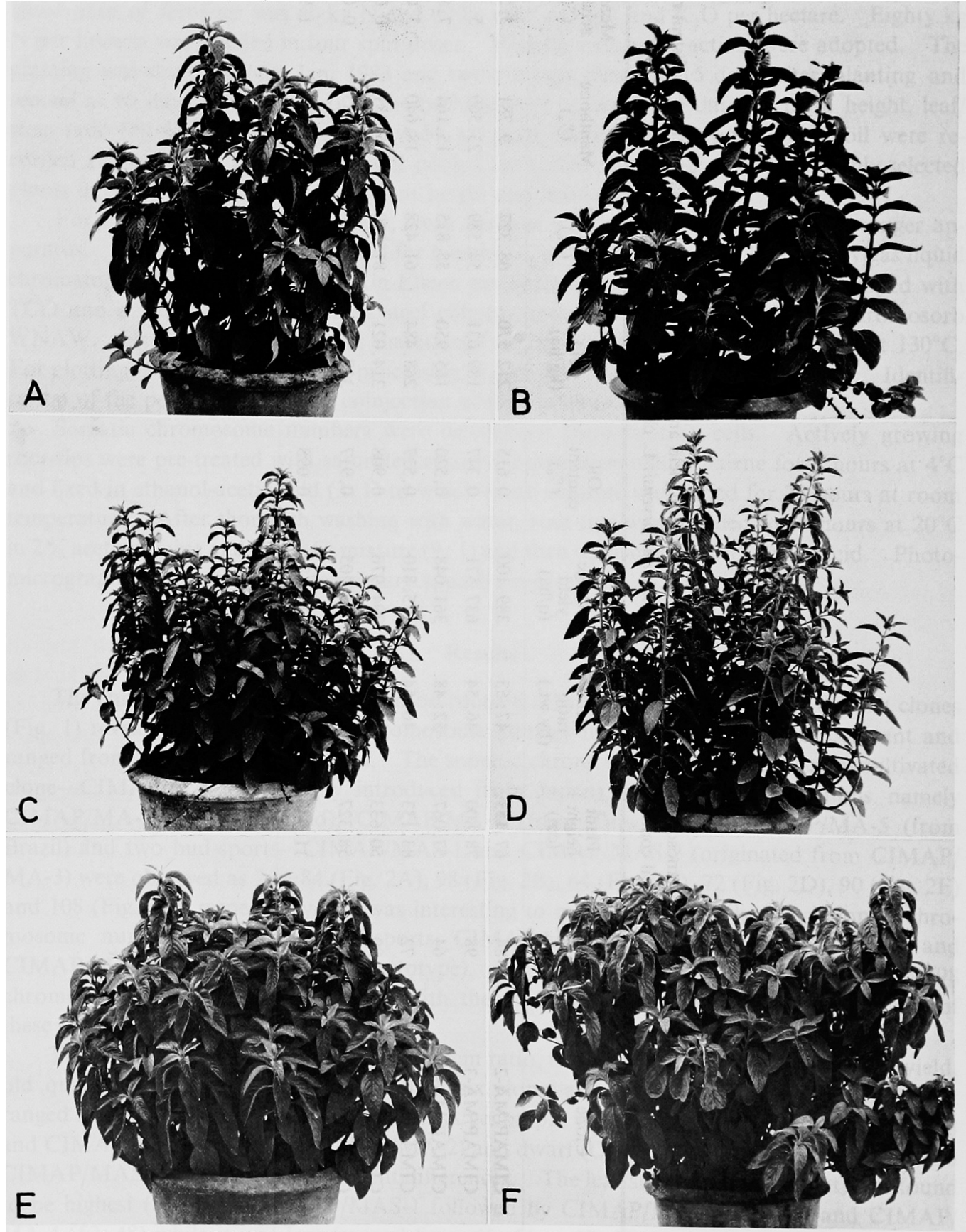

Fig. 1. Plants of different $M$. arvensis clones. A, CIMAP/MA-2. B, CIMAP/MA-3. C, CIMAP/MA-4. D, CIMAP/MA-5. E, CIMAP/MAS-1. F, CIMAP/MAS-2. 
recorded to be CIMAP/MA-3. So far as the oil yield was concerned, it was highest (338.544 $\mathrm{kg} / \mathrm{ha}$ ) in case of CIMAP/MAS-2 which did not differ significantly from CIMAP/MAS-1 and CIMAP/MA-5 with 314.021 and $268.484 \mathrm{~kg} / \mathrm{ha}$ oil yields, respectively. Similarly, the differences in oil yield amongst the rest three clones (CIMAP/MA-2, CIMAP/MA-3 and CIMAP/

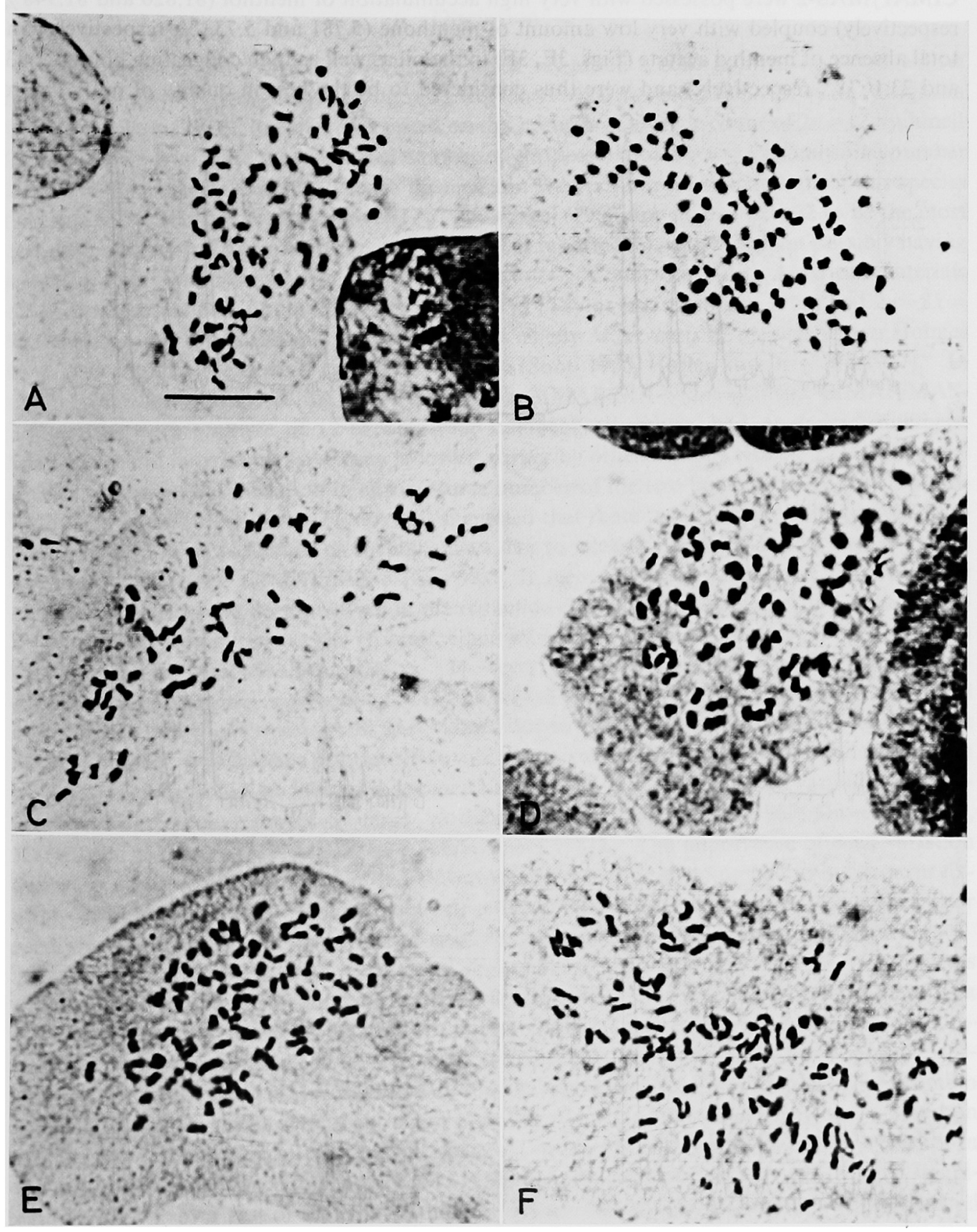

Fig. 2. Somatic chromosome numbers at metaphase of $M$. arvensis. $A, 2 n=84$ (CIMAP/MA-2). B, $2 n=98$ (CIMAP/MA-3). C, $2 n=64$ (CIMAP/MA-4). D, $2 n=72$ (CIMAP/MA-5). E, $2 n=$ 90 (CIMAP/MAS-1). F, $2 n=108$ (CIMAP/MAS-2). Bar represents $10 \mu$. 
MA-4) were non-significant. However, CIMAP/MA-4 gave the lowest $(165.950 \mathrm{~kg} / \mathrm{ha})$ oil yield.

Values for the quantity, expressed in percentage of the whole oil, of the three major oil constituents namely menthol, menthone and menthyl acetate obtained through GLC assays (Fig. 3) and congealing point of the oil (Table 1) revealed that both CIMAP/MAS-1 and CIMAP/MAS-2 were possessed with very high accumulation of menthol (81.820 and $81.948 \%$, respectively) coupled with very low amount of menthone (5.781 and $5.733 \%$, respectively) and total absence of menthyl acetate (Figs. 3E, 3F) in the oil as well as high congealing point ( 22.833 and $23.167 \%$, respectively) and were thus considered to be the best in quality of oil. The re-
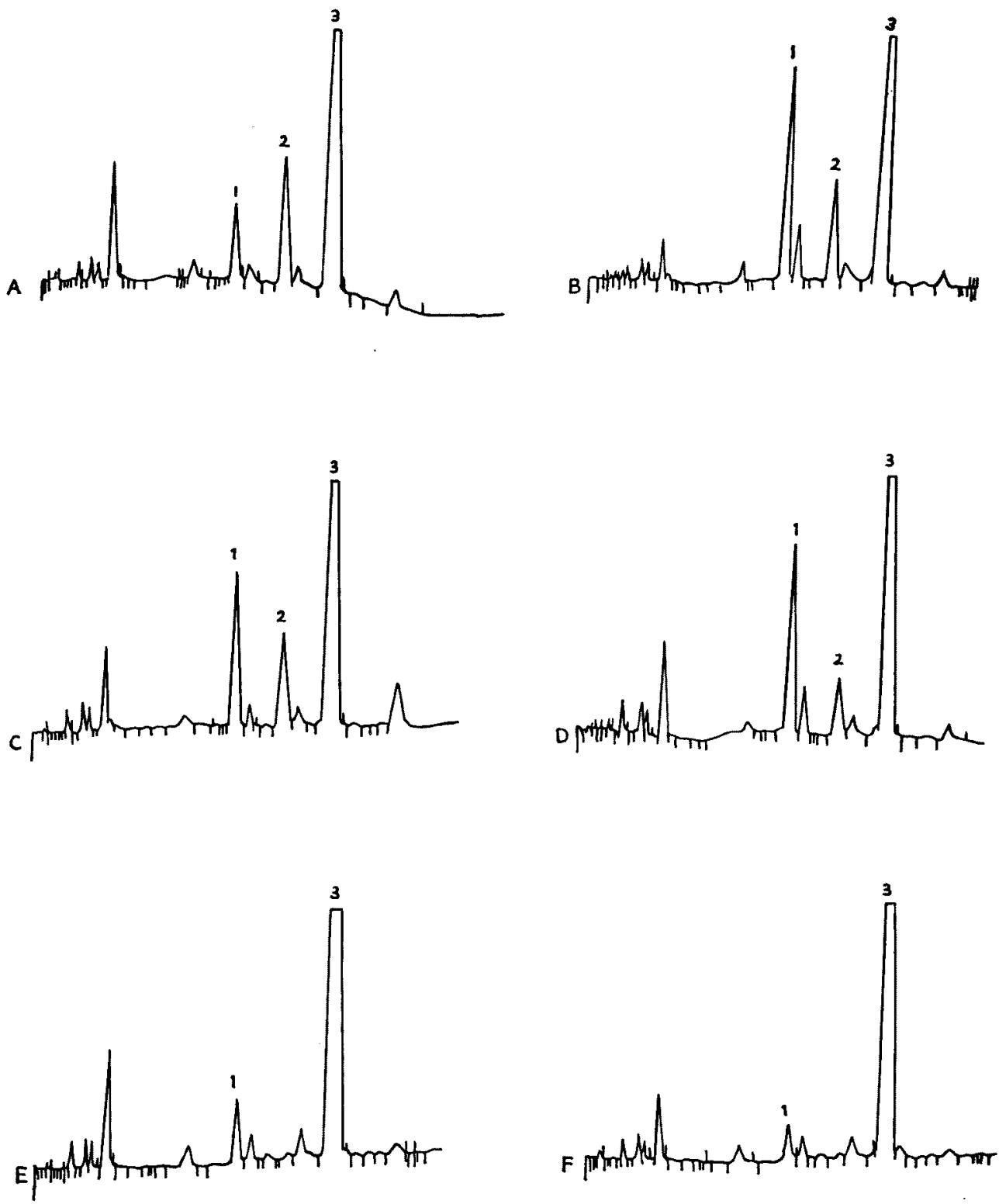

Fig. 3. Chromatograms of oils of $M$. arvensis. A, CIMAP/MA-2. B, CIMAP/MA-3. C, CIMAP/MA-4. D, CIMAP/MA-5. E, CIMAP/MAS-1. F, CIMAP/MAS-2. Peaks marked at 1,2 and 3 show menthone, menthyl acetate and menthol respectively. 
maining four clones differed from each other in respect of their oil composition. However, highest quantity of one of the three major constituents of oil viz. menthol $(81.948 \%)$, menthone $(23.569 \%)$ and menthyl acetate $(7.840 \%)$ was recorded for CIMAP/MAS-1 (Fig. 3E), CIMAP/ MA-3 (Fig. 3B) and CIMAP/MA-4 (Fig. 3C), respectively.

\section{Discussion}

Chromosome counts for $M$. arvensis complex suggested a base number of $x=12$ with a range of numbers from diploid to octoploid (Morton 1956, Ouweneel 1968, Harley and Brighton 1977). Morton (1956), however, suggested on the strength of a single count of $2 n=12$ by Junell (in Löve and Löve 1942) that the basic number might possibly be $x=6$. Chromosome number $2 n=6 x=72$ has been reported for both Eastern and Western European materials of this species (Morton 1956, Harley and Brighton 1977). Ouweneel (1968) found $2 n=6 x=72$ to be the most common number in Dutch $M$. arvensis. He further reported $2 n=90$, in a plant possibly having a hybrid origin, and also another count of $2 n=2 x=24$. Counts for North American materials of $M$. arvensis varied with $2 n=3 x=36,2 n=6 x=72$ (Taylor and Mulligan 1968) and $2 n=8 x=$ 96 (Mulligan and Cody 1968). Asiatic specimens chiefly $M$. arvensis forma piperascens Holmes have been found to be octoploid with $2 n=8 x=96$ (Sobti 1965, Harley and Brighton 1977). In the present study, except CIMAP/MA-2 $(2 n=84)$, CIMAP/MA-5 $(2 n=72)$ and CIMAP/MAS$2(2 n=108)$ with multiple of 12 chromosome numbers, all others had aneuploid numbers. Such aneuploid individuals have been recorded earlier by other workers (Ruttle 1931, Ouweneel 1968). The recorded variation in chromosome number of the two bud-sports-CIMAP/MAS$1(2 n=90)$ and CIMAP/MAS-2 $(2 n=108)$ suggested that these two cytotypes might have orginated by addition or reduction of chromosomes due to irregular mitosis in the bud meristem of the parental clone CIMAP/MA-3 $(2 n=98)$. It seems probable, therefore, that the same mechanism might have been involved in the reduction of chromosome number in CIMAP/MA2 ( $M$. arvensis forma piperascens Holmes, clone introduced from Japan) from 96 (Sobti 1965) to 84 during its vegetative propagation. However, the possible reasons for the variation recorded in chromosome numbers of CIMAP/MA-3 $(2 n=98)$, CIMAP/MA-4 $(2 n=64)$ and CIMAP/MA-5 $(2 n=72)$ remain still unexplained due to the paucity of information on the mode of their origin. Interspecific hybridization and participation of reduced and unreduced pollen in series of crosses and back-crosses are another possible sources of a large variation in chromosome numbers as reported by many workers (Morton 1956, Olsson 1967, Ouweneel 1968, Harley and Brighton 1977, Tucker and Fairbrothers 1981). The importance of such variation in chromosome number brought about by introgression and/or sporting and its subsequent fixation through vegetative propagation irrespective of the nature and extent of pollen and/or seed sterility towards the evolution of new $M$. arvensis cytotypes merits consideration.

In the present investigation, differences among the six genotypes recorded for various traits (Table 1) indicated a genotypic control for these attributes. The direct implications towards a positive correlation between variation in chromosome number, yield potential and oil composition could not be ascertained. In most of the clones, leaf/stem ratio had a positive correlation with oil content which might be due to the increase in total leaf area, where maximum essential oil glands are located, resulting in more oil glands and thus more oil yield. Based on relative performance for oil content, oil yield, exceptionally high accumulation of menthol in the oil (Table 1), the two bud-sports (CIMAP/MAS-1 and CIMAP/MAS-2) were proved significantly superior over rest of the clones studied. As a result, CIMAP/MAS-1 has been released for commercial cultivation.

The biogenetic relationship of compounds found in Mentha oils has been postulated by Hefendehl and Murray (1976). In this sequential biosynthetic series each conversion of one 
compound to the next compound is controlled by one or more genes which themselves control the formation of the necessary enzymes. The expression of these genes is further influenced by modifying genes. The dominant $P$ gene allows the conversion of pulegone to menthone, the dominant $R$ gene allows the conversion of menthone to menthol, whereas the dominant gene $E$ allows the conversion of menthol to menthyl acetate. In the present study, with the exception of CIMAP/MAS-1 and CIMAP/MAS-2, the remaining four clones with varying chromosome numbers produced the same three major oil constituents in different quantitative amounts suggesting thereby that they might have possessed the same basic genes but with different allelic combinations. High accumulation of menthol resulted from no conversion of menthol to menthyl acetate in the two bud-sports (CIMAP/MAS-1 and CIMAP/MAS-2) indicates that these two clones might be homozygous for recessive $e$ gene which completely stopped the conversion of menthol to menthyl acetate thus resulted in the accumulation of menthol. Similar result in Mentha citrata hybrids where a single dominant gene $L m$ almost entirely blocked the conversion of limonene to carvone has been reported (Lincoln et al. 1971).

\section{Summary}

Six morphologically distinct genotypes of Mentha arvensis L. consisting of four clones introduced from Japan (CIMAP/MA-2), Thailand (CIMAP/MA-3), Taiwan (CIMAP/MA-4) and Brazil (CIMAP/MA-5) and two bud-sports (CIMAP/MAS-1 and CIMAP/MAS-2) of a Thailand clone (CIMAP/MA-3) were studied under uniform environmental conditions for somatic chromosome numbers, yielding ability and essential oil quality. The somatic chromosome number in these genotypes ranged from $2 n=64$ to 108. Three clones viz. CIMAP/ MA-2 $(2 n=84)$, CIMAP/MA-5 $(2 n=72)$ and CIMAP/MAS-2 $(2 n=108)$ possessed chromosome numbers multiple of the base number $(x=12)$ while the remaining three clones (CIMAP/ MA-3, CIMAP/MA-4 and CIMAP/MAS-1) contained aneuploid numbers such as $2 n=98$, 64 and 90 , respectively. The results on chromosome number variation in the two bud-sportsCIMAP/MAS-1 $(2 n=90)$ and CIMAP/MAS- $2(2 n=108)$ suggested that these two cytotypes might have originated by addition or reduction of chromosomes due to irregular mitosis in the bud meristem of the parental clone-CIMAP/MA-3 with $2 n=98$. It is likely that a similar mechanism for reduction of chromosome number from $2 n=96$ to $2 n=84$ might have operated in CIMAP/MA-2. The relevance of a large variation in chromosome number brought about by introgression and sporting and its subsequent fixation through vegetative propagation in evolving the observed cytotypes in $M$. arvensis is discussed. The variation among the six genotypes for various characters like plant height, leaf/stem ratio, fresh herbage yield, oil content, oil yield, oil composition and congealing point of oil indicated a genotypic control for these traits. CIMAP/MAS-1 and CIMAP/MAS-2 with significantly high oil content, oil yeild and exceptionally greater amount of menthol in the oil proved significantly superior over rest of the genotypes. The absence of menthyl acetate in the oil of CIMAP/MAS-1 and CIMAP/MAS-2 quite contrary to the remaining four clones is interpreted in the sence that these two genotypes might be in possession of homozygous recessive gene ' $e$ ' responsible for completely blocking the conversion of menthol to menthyl acetate.

\section{Acknowledgement}

The authors are grateful to Dr. Akhtar Husain, Director, Central Institute of Medicinal and Aromatic Plants, Lucknow, for his valuable guidance and keen interest throughout the investigation. 


\section{References}

Dutta, P. K. 1971. Cultivation of Mentha arvensis in India. Flavour Industry 2: 233-240, 245.

Guenther, E. 1949. The Essential Oils. Vol. 3, D. Van Nostrand, New York, pp. 640-663.

Handa, K. L., Kapoor, L. D. and Abrol, H. L. 1954. A short note on Japanese mint raised in Kashmir. Indian J. Pharm. 16: 32-33.

Harley, R. M. and Brighton, C. A. 1977. Chromosome numbers in the genus Mentha. Jour. Linn. Soc. Bot. 74: 71-96.

Hefendehl, F. W. and Murray, M. J. 1976. Genetic aspects of the biosynthesis of natural odours. Lloydia 39: $39-52$.

Husain, A. 1982. A quarter century of research on essential oil crops in India. Indian Perfumer 26: 17-28.

Ikeda, N. and Ono, S. 1967. Genome analysis of Mentha japonica Makino (Genome analysis in the genus Mentha, Part 5). Jap. J. Breed. 17: 182-188.

Kapoor, L. D., Handa, K. L., Chandra, I. and Abrol, B. K. 1955. Cultivation of Mentha arvensis in Jammu and Kashmir. J. Sci. Ind. Res. 14A: 374-378.

Lincoln, D. E., Marble, P. M., Cramer, F. J. and Murray, M. J. 1971. Genetic basis of high limonene-cineole content of exceptional Mentha citrata hybrids. Theor. Appl. Genet. 41: 365-370.

Löve, A. and Löve, D. 1942. Chromosome numbers of Scandinavian plant species. Botaniska Notiser 95: $19-59$.

Mehra, B. K. 1982. Mentha oil and menthol production in India-Past, present and future. In "Cultivation and Utilization of Aromatic Plants", edited by C. K. Atal and B. M. Kapur (Regional Research Laboratory (C.S.I.R.), Jammu-Tawi), pp. 241-277.

Morton, J. K. 1956. The chromosome numbers of the British Menthae. Watsonia 3: 244-252.

Mulligan, G. A. and Cody, W. J. 1968. In Löve, A., IOPB chromosome number reports. Taxon 17: 285-288.

Olsson, U. 1967. Chemotaxonomic analysis of some cytotypes in Mentha $\times$ verticillata complex. Botaniska Notiser 120: 255-267.

Ouweneel, W. J. 1968. Cytotaxonomic studies in the genus Mentha in the Netherlands. Proc. K. Nederlandse Akademie van Wetenschappen (C) $71: 184-188$

Ruttle, M. L. 1931. Cytological and embryological studies of the genus Mentha. Gartenbauwissenschaft 44: 428.

Sobti, S. N. 1965. Chromosome numbers in species of Mentha. Proc. Indian Acad. Sci. 62 B: 145-148.

Taylor, R. L. and Mulligan, G. A. 1968. Cytological aspects of the vascular plants. Flora of the Queen Charlotte Islands 2: 102. Ottawa.

Tucker, A. O. and Fairbrothers, D. E. 1981. Aeuploid series in an $F_{1}$ interspecific hybrid progeny of Mentha (Lamiaceae). Bull. Torrey Bot. Club 108: 51-53. 